\title{
Nutrigenomics for Global Health: Ethical Challenges for Underserved Populations
}

This is a preprint of an article published in the journal Current Pharmacogenomics and Personalized Medicine, 2009; 7(3): 205-14 (URL:

http://www.bentham.org/cppm/contabs/cpg7-3.htm\#6)

B. Godard ${ }^{1, *, * *}$ and T. Hurlimann ${ }^{1, *}$

1 Department of social and preventive medicine, Bioethics Programs, Faculty of Medicine, University of Montreal, Montreal, Canada.

Keywords: Developing countries - Ethics - Global health - Nutrigenomics - Public health

* These authors contributed equally to this work.

** Corresponding author: Dr. Béatrice Godard, Department of social and preventive medicine, Bioethics Programs, Faculty of Medicine, University of Montreal, Montreal, Canada, CP 6128, succ. Centre-Ville, Montréal, QC, Canada, H3C 3J7; Tel: (514) 3436832; Fax: (514) 343-5738; Email: beatrice.godard@umontreal.ca 


\section{Abstract}

Nutrigenomics covers disparate fields of nutrition science and has been defined in many different ways. In fact, this emerging field of science has multiple facets, many of which do not generate the same ethical issues. In particular, different ethical issues emerge concerning the extent to which nutrigenomics may actually improve global health, i.e., in terms of worldwide improvement of health, reduction of disparities, and protection against global threats that disregard national borders. Nutrigenomics raises many hopes and expectations on that score. However it remains unclear and controversial whether nutrigenomics studies and their actual or potential applications will actually benefit developing countries and their populations. Different forces may drive the choice of research priorities and shape the claims that are made when communicating the goals or the results of nutrigenomics studies and applications. This article proposes to assess expectations and claims in nutrigenomics, with respect to their respective potential impact on global health and the ethical issues they raise. Nutrigenomics is and should be more than premature claims and much debated promises about personalized nutritional interventions on individuals. Beyond questionable commercial claims, nutrigenomics is also knowledge about and recognition of the considerable impacts of underfeeding and malnutrition on the genome (and epigenome) integrity and stability. As such, nutrigenomics research is a valuable opportunity to revive and give strength to the debate about the unacceptable consequences of hunger and malnutrition worldwide, and to support a newly and potentially significant convergence in research priorities that could benefit both developed and developing countries. 


\section{Introduction}

Nutrigenomics is a new application context for genomics technologies that focuses on the bidirectional study of genetic factors influencing host (individuals' or populations') responses to diet as well as effects of bioactive constituents in food on host genome and gene expression [1, 2]. This bidirectional approach to the study of genome-diet interaction creates a dual avenue for tangible nutrigenomics applications. Nutrigenomics is often described as one of the latest applications of genomics technologies in the field of personalized health interventions or personalized medicine, following the science of pharmacogenetics and pharmacogenomics. Yet, as it will be shown in this article, nutrigenomics goes beyond personalized health interventions. It covers disparate fields of nutrition science, which may pursue different goals and thus have multiple facets. Consequently, different ethical issues emerge, particularly in regard to the extent to which nutrigenomics may improve global health.

There is no common understanding of the term "global health" [3]. Global health "is a field that encompasses [...], processes, and institutions needed to create the conditions for people throughout the world to attain the highest possible level of physical and mental health. The field seeks to facilitate health-promoting behaviour among the key actors that significantly influence the public's health, including international organizations, governments, businesses, foundations, the media, and civil society" (Modified from Gostin and Taylor, 2008, [4, p. 55]). Gostin and Taylor [4] consider that global health mainly results from the globalization of public health beyond national borders. Other distinctions have been made between public health and global health, but it is worth noting that while global health raises specific ethical, social, legal and economic challenges, it also targets whole populations and as such, it also generates issues that commonly arise within national public health agendas. Therefore, considerations relating to public health remain crucial when addressing global health. In this article, focus will be put on worldwide improvement of health, reduction of disparities, and protection against global threats that disregard national borders, both in terms of public health and global health. 
Many promises have been made regarding the potential outcomes of nutrigenomics research. Some of them will likely be fulfilled while others must be considered as premature until we have a full understanding of the interactions between genomics, nutrition and health. There are, of course, compelling reasons to think globally in terms of health when we address these promises and face the challenges that derive from them.

Firstly, despite their demonstrated increasing rates worldwide, chronic diseases remain surprisingly neglected in the global health agenda [5]. Because of changes in dietary and lifestyle habits - a phenomenon that can be linked to the whole globalization process - developing countries now face a fast "epidemiological accumulation" [6, p. 14] of non-communicable and infectious diseases and must cope with urgent and competing health priorities. Non-communicable diseases (NCDs) - especially cardiovascular diseases, cancers, chronic respiratory diseases and diabetes - caused $60 \%$ of all deaths globally in 2005 (estimated at 35 million deaths). Total deaths from NCDs are projected to increase by a further $17 \%$ over the next 10 years [7, 8]. By 2020 , it is predicted that NCDs will account for 80 percent of the global burden of disease, causing seven out of every 10 deaths in developing countries [9]. This places a considerable (double) burden on limited health budgets, in particular in emerging economies. Thus, chronic diseases cannot be seen anymore as a national health concern in rich countries only and the promises of nutrigenomics must be addressed with respect to this current growing epidemic, both in developed and developing countries.

Secondly, according to the Food and Agriculture Organization of the United Nations (FAO), food prices remain high in developing countries [10-12]. While commodity prices have fallen back from their peaks since 2008 , they remain substantially higher than a year ago and in most cases more than double their level in mid-2006 [13]. Moreover, the number of undernourished people has actually increased by 75 million to more than 920 millions in 2007 [14]. Concerns resulting from this situation are exacerbated by striking socioeconomic disparities and inequities in access to healthcare, let alone genomics technologies, as much as to basic nutrition between rich and poor countries and within 
developing countries themselves. Nutrigenomics research and its potential global applications cannot be considered without respect to this ongoing food crisis, global recession, and urgently needed measures aiming to fight hunger, malnutrition, poverty and inequities both in access to food and healthcare.

The assessment of the potential impact and applications of nutrigenomics for global health "demands a vision that reaches beyond the research horizon" [15]. As stated by many authors, it is challenging to determine to what extent genomics, including nutrigenomics, may result in evidence-based public health strategies [16-18]. Many chronic diseases are multifactorial and social and environmental determinants of health are worth emphasizing as genetic/genomic factors. At this stage, large-scale genomic and epidemiological studies are still needed for translating scientific discoveries into global health interventions. Yet, rapid advances in genomics and accompanying technologies are triggering a shift in the comprehension of health and disease as well as in the understanding of new approaches to prevention and therapy [16].

Moreover, nutrigenomics for global health demands a conceptual shift in both genomics, nutrition science, and public health: genomics needs to understand how it can include nutrition science as well as public health aspects in its agenda while nutrition science and public health need to analyze how genomics changes the concept of public health concerning nutrition. It also demands a conceptual shift in bioethics: it will require a proportional balance between providing strong protection of individuals' and populations' interests and enabling them to benefit from nutrigenomics advancements, not only in regard to their availability but also to their accessibility both in developed and developing countries.

The integration of nutrigenomics into global health programs will be one of the most important future challenges for health-care systems and will require organized efforts of society. A major ethical question is how these scientific endeavors will be handled in order to develop and promote sound and well thought-out global health programs. 
Advances in our understanding of the human genome have raised high hopes both for the prediction and prevention of diseases long before they occur [19], and for the development of more effective treatments [20, 21]. Similarly, expectations raised by nutrigenomics are high. Potential or current applications of this new field of science have been described and communicated in different ways by various stakeholders. Yet, in order to avoid serious adverse consequences, including the loss of public confidence in genomics (and its current clinical evidence-based applications), it is urgent to distinguish

goals and expectations from premature or unreasonable claims, as well as to identify those future applications that are likely to be the most promising in terms of global health.

\section{Nutrigenomics: goals and expectations}

Since the advent of nutrigenomics, many (if not most) claims relating to its promises have emphasized the use of personalized nutrition interventions in order to prevent the onset of severe chronic diseases in individuals or populations with specific genetic predispositions. In this respect, nutrigenomics, as it is stated, "can be used [not only] to prevent, [but also to] mitigate or cure chronic disease", through personalized "dietary intervention based on knowledge of nutritional requirement, nutritional status and genotype" [22]. As such, nutrigenomics targets apparently healthy individuals with genetic predispositions for specific diseases or health conditions, but also patients in whom a chronic disease has already appeared. Thus, for instance, some authors argue that nutrigenomics could eventually allow us to give specific nutritional advice to population groups in which the frequency of a deleterious mutation is high [23, p. 459]. Authors even anticipate the use of gene therapy in the field of nutrigenomics, arguing that "recombinant genes might also be implanted in people to better adapt them to a given diet" or to prevent certain deficiencies resulting from genes-nutrition interactions [24].

The most targeted diseases or health conditions in nutrigenomics research are notably various forms of cancer, diabetes, obesity, gut disorders, and cardiovascular diseases. Nevertheless, it must be stressed that other nutrigenomics studies - mostly preclinical - 
focus on the interactions between specific nutrients, gene expression (including agerelated gene-expression alteration) and synaptic plasticity, cognitive development, and brain disorders such as Alzheimer's disease or, more recently, Down syndrome [25-27].

Yet, some private firms that are already (and likely prematurely) selling nutrigenetics tests to the public (see Box 1) have significantly broadened the scope of allegedly personalized nutrigenomics applications by suggesting that nutrigenetics tests can be used to "control health and well-being" in general [37], but also to help people with genetic predispositions to "joint issues", "thinning bones", "inherited depression tendency", and "propensity to crave sugar" [38]. Some even emphasize the promises of nutrigenomics in terms of physical, cognitive and even aesthetic enhancement. Thus, allegedly, in the future, a juice designed according to a consumer's "genetic chemistry" could help the latter "to appear younger and more vigorous", "to be mentally sharper" and "to be more appealing to romantic partners" [39]. 


\section{Box 1}

\section{Direct-to-consumer "nutrigenetics" tests}

Much has been said and written about the growing market of direct-toconsumer (DTC) genetic tests lately [28-32]. As their name indicates, these tests are offered to the public directly, namely with no involvement of a licensed physician. Consumers are approached through advertisements on the Internet or other media and attracted by claims whose validity or foundation generates many concerns. The field of nutrigenomics has not been immune to this commercial marketing, several private firms being offering "nutrigenetics tests" and dietary recommendations or designed vitamins formulas that would be, allegedly, tailored to their consumers' genetic profile and predispositions to specific multifactorial diseases. Major concerns have been expressed in this regard, in particular with respect to:

- The validity and clinical utility of these tests, and the lack of standard of evidence that would allow an appropriate assessment of the efficacy and beneficence of "nutrigenetics tests";

- The lack of medical and genetic counseling to the consumer pre- and post-testing and, by the same token, concerns about the validity of the consent given by the consumers and the risks involved by the potential misinterpretation of the test results;

- The validity of dietary recommendations allegedly based on consumers' genetic profile;

- The promotion of purchasing dietary supplements that are often overpriced, and even potentially harmful for the consumer's health;

- The risks of deceit and fraud, if not outright scams, that result from biased commercial advertisement;

- The general lack of oversight and quality control issues.

- The protection of the privacy and confidentiality of consumers [33].

Despite restrictive recommendations and policies [34-36] and the enforcement of more strict regulations in certain countries and certain states in the U.S. [28], this market does not seem to run out of steam. As argued in this paper, beyond justified and serious concerns about the current validity of "nutrigenetics tests", it must be stressed that this market is inscribed in a nutrigenomics approach that mainly targets well-off consumers and focuses on individual (and mostly premature!) applications. As such, it does not only generate serious ethical issues about equity and justice in access to nutrigenomics applications, but it will also likely not benefit global health or developing countries. 
Knowledge resulting from nutrigenomics research has also raised new expectations regarding the development and/or the engineering of food that would contain the optimal concentration of certain micronutrients (for individuals or given populations), for instance, in order to meet human needs, prevent certain diseases and promote optimal health in sustainable ways [24, 40-42]. As argued by some authors, certain genomics technologies in combination with other-omics sciences, have the potential to generate a more complete picture of the composition of food and feed products, to optimize crop trait development, and to enhance diet and health [43]. Here, nutrigenomics lays at the crossroads of plant nutrition research, human and plant molecular biology, and even food processing and production, agriculture sciences and genetic engineering [44]. In this field, while it may be claimed that nutrigenomics knowledge could be of interest in the engineering of genetically modified organisms, expectations have mainly been linked to functional foods and nutraceuticals. Agriculture and Agri-Food Canada define functional foods as conventional foods that have physiological benefits and/or reduce the risk of chronic diseases beyond basic nutrition. Nutraceuticals are defined as products isolated or purified from foods, generally sold in medicinal forms not usually associated with foods, and that have a physiological benefit or provide protection against chronic diseases [45]. Yet, there is no consensus on such definitions and it is plausible that nutrigenomics knowledge might be used to develop and design a new generation of functional foods and nutraceuticals. It must be noted that some private firms already offer vitamins or vitamin formulas allegedly designed according to their consumers' unique genetic profile ("vitamins that are uniquely yours based on your oneof-a-kind genetic code" [46]) (See Box 1). In another perspective, it has been suggested that (nutri)genomics knowledge could bring useful information to control meat production and improve meat quality in nutritionally restricted environments. Studies have been conducted to understand the interactions between genes, nutritional restriction and muscle development in livestock and the capacity to exhibit compensatory growth after restriction is relieved [47].

Finally, it is crucial to stress that nutrigenomics does not (and should not) only target individuals with genetic predispositions for specific diseases or health conditions that 
could be triggered or influenced by dietary factors. Indeed, beyond personalized applications, nutrigenomics can also be described as a tool used to study and explain the mechanisms by which diet, food, nutrients and other dietary chemicals impact the integrity or structure of the human genome and/or alter gene expression in each of us and, by the same token, in whole populations, regardless of pre-existing genetic susceptibilities for specific diseases. The best illustration of this important goal is the growing research in epigenomics and nutrition, aiming to study and explain how nutrition (including malnutrition and undernutrition) in utero and in early postnatal life may influence health and the onset of chronic diseases later in life [48-53]. Such an example also demonstrates that the goal of nutrigenomics is not just about avoiding the onset of specific diseases in individuals with pre-existing genetic predispositions that could be triggered by food. Nutrigenomics should also aim to promote optimal health on a global scale and prevent damages on the genome's stability and integrity that could create or increase genetic predispositions or risks to develop chronic diseases.

All expectations and claims relating to current or future potential nutrigenomics applications must be assessed according to their respective merit and, in particular with respect to the scientific bases on which they are grounded. In this respect, while much research is still needed in this field, it is crucial to keep in mind that there are already well-documented examples of clinically significant nutrigenetics interactions. Severe adverse reactions to certain foods resulting from specific individual genetic variations have been reported and scientifically demonstrated in such cases as inherited deficiency of glucose-6-phosphate dehydrogenase (favism) [54, p. 47] or phenylketonuria [55]. These examples illustrate how genetic differences may explain why certain individuals suffer from severe reactions to specific foodstuff, while others do not. Moreover, the number of genes identified by their nutrigenomics potential has significantly increased in the recent years [56]. Potential and useful nutrigenomics applications in public health are also supported by the results of recent studies that show, among other examples, that it may be possible to identify subgroups that would actually benefit from folic acid supplements [57], or that a minimum amount of olive oil might be needed to turn on genes that contribute to protect individuals against atherosclerosis [58]. 
Given the aforementioned expectations including questionable commercial claims, but also already well-documented evidence of clinically relevant gene-nutrition interactions, which nutrigenomics research and applications may actually promote global health and benefit developing countries? To attempt to answer such a question, it is first necessary to address the complexity of nutrigenomics itself and the current limitations of its potential applications in public health. A lack of appreciation of the complexity of this science and its potential applications, but also a lack of consideration of the context in which it develops may lend itself to premature claims that could occur at the expense of realistic promises for global health and developing countries.

\section{Nutrigenomics and public health: complexity and uncertainties}

The possibility of a more efficient science of the prevention and surveillance of diseases also illuminates the field of nutrigenomics for global health, where nutrigenomics knowledge could provide tools enhancing the capacity of public health authorities to promote health and prevent diseases. However, a major challenge for public health authorities will be the effective integration of nutrigenomics information into public health responses, especially for the identification/treatment of chronic diseases that constitute a serious burden to populations and are costly for health care systems. Also, in addition to the well-known complexity of genomics association studies $[59,60]$ and uncertainties about the efficacy of potential nutrigenomics applications in public health [61], nutrigenomics research and applications face significant challenges as one considers the complexity and variability of nutrition and foods and their multiple targets $[62,63]$.

Although nutrigenomics could initiate a transformation of the "one size fits all" paradigm in global health, there are concerns about "blind faith" in or overly optimistic views of scientific progress resulting from the most recent research in this field [64]. Some commentators state that it is still premature to associate nutrigenetics variants with the expression of complex diseases [18]. They argue that, given the interaction of the

genetic and environmental factors behind complex diseases, the attempts to link relevant genes with the expression of such diseases are invariably simplistic and offer 
little real hope for practical diagnostics and treatments. Moreover, it would be very challenging to anticipate individuals' reactions to receiving genetic information that is probabilistic and derived from multiple sources. Nutrigenomics illustrates the complexity of biological processes, the importance of gene-gene and gene-environment interactions. Its power must also lay in the application of other mainstream public health interventions - promoting healthy behaviors or acting on environmental factors directed at sub-groups of populations segmented according to their risks. As a result, it is important not to forget that in order to prevent a fatalistic attitude from at-risk people, nutrigenomics applications in public health must also consider other health determinants.

Nutrigenomics forms a complex field of knowledge, susceptible to being misunderstood by non-experts. This is a major challenge in public health. The notion of an evaluation of risks and susceptibilities better conveys the complexity of current knowledge about multifactorial diseases than the prediction thereof. Nonetheless, the idea of risk remains abstract and is difficult to grasp for non-experts. The diversity of their perceptions reveals itself in the literature [65-67]. Emphasizing these nuances buttresses the recommendation to spread genomic knowledge so as to inform and educate those nonexperts that will be called upon to participate in the process of integrating nutrigenomics into global health [66], but also to raise the awareness of experts on the impact that language can have, whether it be when reporting results, or in direct contact with people, either in a clinical work or in a preventive context.

Such challenges illustrate the current limitations and uncertainties linked to the potential efficacy, risks and benefits of nutrigenomics applications in public health systems within national borders themselves, but such limitations are obviously also relevant when it comes to addressing the promises of nutrigenomics for global health. The long-term development of global health genomics will require an appropriate integration of the scientific, clinical, economic, social and ethical dimensions as well as the strengthening of global health ethics. In this perspective, in a recent article, Gwinn and Khoury [68] identified three levels for the integration of genomics into public health. Although the 
work of Gwinn and Khoury [68] is directed at public health in the United States of America, it might also be relevant for global health. The first is related to the possibility of conducting population health research in genomics. The impact of new findings in genomics could be limited without large cohort studies confirming these findings and illustrating the risk factors related to specific diseases. The collaboration of different fields of research is essential and would increase the impact of research in global health. The second level concerns the development of scientific evidence regarding the value of genomic information. This emphasizes the importance of disseminating information emerging from genomics research to ensure that public health professionals receive a clear demonstration of the clinical validity and utility of genomics. It implies that health professionals should have access to training on new genomic tools that could bring significant changes in global health. A number of technologies have proven their clinical value, but to be used properly, public health institutions need personnel trained in using complex information [69]. For this purpose, international networks are being developed to spread information about genomics and global health (e.g.: GRAPH Int. [70]). The third level refers to the integration of genomics into global health practice. According to the authors, the realization of this process requires "careful policy planning and development that recognizes the complexity of genomics while building on approaches that have been successful in evaluating other health technologies" [68]. Recently, a strengthening of public health ethics has been launched at the US Centers for Disease Control and Prevention to address specific public health program concerns, including genomics [71]. The authors anticipate that as public health ethics activities grow, benefits will be seen in greater participation and partnership with affected stakeholders and strengthened public trust in health recommendations.

\section{The major ethical challenges of nutrigenomics for global health: Stigmatization, discrimination and social justice}

In addition to scientific complexity and current uncertainties, nutrigenomics applications for global health face major ethical challenges. In order to keep its promise of improving health, nutrigenomics needs to see its scientific progress harmonized with human dignity and social justice as expressed through adherence to fundamental ethical 
principles. Some of the ethical issues raised by nutrigenomics will be the same as those raised by the development of genomics research and applications in general: notably, genetic exceptionalism and reductionism [72-74], protection of privacy and confidentiality, and issues relating to autonomy and informed consent in clinical care and research. While such challenges have just begun to be addressed in regard to nutrigenomics (see for instance, [1, 23]), other ethical issues such as stigmatization, discrimination and social justice may well arise specifically or with more strength during the development of nutrigenomics applications for global health, in particular in emerging economies and vulnerable populations [see also Box 2].

The implementation of more accurate methods of prevention and surveillance brings out the stigmatization and discrimination issues encountered in global health ethics. Is there a risk of stigmatizing sub-populations because of their genetic susceptibilities? Will the use of genomics technologies lead to new inequalities among people? Which segments of the population will be subject to surveillance and on what grounds? Even if the risks of stigmatization or discrimination might be exaggerated, the fears might hinder the development of nutrigenomics, thereby restricting its potential benefits for populations. Such questions underline the importance of not loosing sight of the ethical principles at the root of global health ethics [75-77]. Because of the power imparted to public health authorities, the ethical integration of nutrigenomics into global health requires the informed awareness of lay citizens, and eventually their participation in the formulation of public policy in a framework of respect for local and cultural particularities [64]. Otherwise, the situation might evolve toward contributing to social inequalities or causing undesirable harm. Most genetics experts recognize the importance of public awareness $[75,78]$ for avoiding stigmatization and discrimination.

Thereafter, it becomes necessary to reflect on the nature of the terms used in scientific publications and on nutrigenomics websites. Some ways of reporting results, albeit proper from a strictly scientific point of view, can carry messages that are detrimental to certain groups, with the potential to reinforce prejudice and thus be harmful to identifiable social groups, as in the case of racial prejudice [67]. In public health, a constant practical concern leads to special care being taken in how preventive 
messages are conveyed to the public, so as to limit any prejudicial effects on target populations, whether it be through stigmatization, marginalization or an incitement to judgmental attitudes [79].

Moreover, research focusing on Caucasian populations may restrict the range of groups and/or populations that might likely benefit from nutrigenomics developments. As a matter of fact, the genetic diversity of human populations is a challenge to the development of personalized dietary interventions [80]. Small, specific (and likely more vulnerable) groups could become the "orphans" of nutrigenomics. These are major discrimination and justice concerns in nutrigenomics research and potential applications. The same is true if nutrigenomics research focuses on western diets or foodstuffs that cannot be produced or that are not accessible or culturally relevant to populations in developing countries.

In developing countries and emerging economies, the potential stigmatisation and discrimination also relies on the non-access to nutrigenomics services. Of particular interest is how nutrigenomics advances will affect the health of people living in the developing countries. In fact, genomics and related technologies should be used to narrow the existing unethical inequities in global health [81]. The reality that much of the advances in genomics were made, and in part are owned, by the developed world has given rise to the concern that a genomics divide will be created that will further widen the equity gap in health between rich and poor nations. In this respect, current patents and market exclusivity systems raise serious ethical issues, notably in terms of global justice. Similar concerns have been expressed in the field of pharmacogenetics [82], for instance, and will not be developed in this article. However, concrete measures and precautions should be taken to address such concerns, failing which there is little doubt that patents on nutrigenomics discoveries could accentuate existing injustices concerning food access and inequities in global health as much as in access to future potential nutrigenomics applications. Nutrigenomics for global health calls for the right of whole populations to benefit from its results, not only individuals who have the sufficient resources to access them. The concept of "common good" might also be part of the 
solution to this ethical dilemma [83]. It stipulates that in an era of liberalism and globalization, the creation of public goods compensates for the inequalities resulting from an inequitable distribution of genomic technologies. "Global public goods are defined as goods that are (...) enjoyable by all without detriment to others" [84]. To some experts, genomic knowledge corresponds to the definition of a public good because it belongs to the common heritage of humanity $[84,85]$, of its "common ownership" and therefore should be a universally accessible resource. In this perspective, by promoting a "common ownership" of genomic knowledge, by improving global health and by tailoring interventions for populations, nutrigenomics developments could be perceived as common goods that respond to the most fundamental needs of individuals (e.g., equity, beneficence) while achieving the goals of the community [84].

Research priorities and access to services are central to global health. Another problem which has to be addressed in this context is the fact that commercial interests are increasingly driving the public research agenda in many developed countries. If unchecked, this trend will discourage scientists in academia from pursuing research directed at improving the health of people living in the developing countries [86, p. 102]. Yet, the current situation has been called the "10/90 divide" [87]. This means that more than 90 per cent of medical research resources are targeted at diseases that account for only 10 per cent of the global burden of disease (i.e., diseases most relevant to the wealthy). Less than 10 per cent of research resources are aimed at those that account for 90 per cent of the global burden of disease (i.e., diseases that mostly affect the poor). In addition to the increased funding needed to make existing (and sometimes inexpensive) medicines more accessible to impoverished populations, a boost in resources is needed to fuel $R \& D$ in areas most relevant to the poor. 


\section{BOX 2}

\section{Are there any ethical challenges unique to nutrigenomics?}

As mentioned in section 4 of this article, many ethical issues raised by nutrigenomics will be the same as those raised by genomics research and its applications. However, other ethical challenges may arise specifically or with more strength during the development of nutrigenomics applications.

First, in addition to the complexity of genomics association studies, nutrigenomics research must tackle the complexity of diets, food components and the multiple targets and effects that different nutrients in different amounts may have in the human body. Thus, the assessment of the scientific validity of research protocols, of the scope of research results and of the efficacy of potential nutrigenomics applications in public or global health is challenging. A lack of any concrete scientific standard of evidence, the uncertainty about the potential efficacy of public health measures based on nutrigenomics applications, a lack of appreciation of the complexity of nutrigenomics, its potential impacts, and the context in which it occurs may create a fertile ground for biohype, namely for unrealistic promises, excessive publicity, and premature claims made in advertising material. It also raises major issues in the way research results are communicated to the public or used by firms to sell nutrigenetics tests to consumers (See Box 1).

Secondly, as stated by Bergmann and colleagues (referring to Holm), "[f]ood means much more than nutrition. Food is enjoyment as cultural and personal identity. A meal is a social event, an important manifestation of relationship with others. This means that food is an important aspect of human happiness and well-being, and not only an instrument of health" [23, p. 456]. In this respect, the development of nutrigenomics along with "personalized medicine" raises major ethical issues. Nutrigenomics can alter our relation to food, by medicalizing food choices and eating behaviours. Moreover, when targeting healthy individuals, nutrigenomics can blur boundaries between health and diseases, and between food and drugs ("nutritional pharmacology"). It broadens the scope of health interventions from patients to individuals by supporting the concepts of "pre-disease" states and "preemptive nutrition" [88].

Finally, in terms of global health, the complexity of potential prevention measures based on nutrigenomics knowledge (see section 3), but also ethical issues relating to social justice and to the risks of stigmatization and discrimination are major challenges on which this paper focuses (sections 4 and 5). While such issues are not unique to nutrigenomics, they appear with a particular strength when it comes to assess the promises of this new field of science. 


\section{What promises for underserved countries?}

Advocates of global health genomics believe that genomics research will foster the development of new genomic tools applicable in a wide variety of public health settings $[42,89,90]$. Genetic services related to maternal and child health have been offered in many countries since the early 1960s [18, 91] and ongoing efforts and the increasing resources devoted to genomics could eventually pave the way for major advances in global health. Yet, knowing that the recognition of the significance of monogenic diseases and birth defects for public health within developing countries is still recent [6, p. 14], it is a safe bet that nutrigenomics research and in particular personalized applications aiming to prevent the onset of multifactorial diseases (such as the diseases targeted by nutrigenomics) may not be perceived as a priority in and for such countries. The current market-driven agenda such as followed by commercial firms targeting well-off individuals who can allow paying for allegedly useful nutrigenetics tests reinforces such perceptions (see Box 1). Such a market does obviously not support global health, equity and social justice, especially when it comes to genetic testing services offered in developing countries by private firms that, despite their localization within the country itself, explicitly target "medical tourists", and not local populations [90].

However, despite such commercial approaches, misconceptions according to which nutrigenomics would not be relevant in developing countries must be dispelled. As previously mentioned in the introduction, in addition to infectious diseases, developing countries are now facing a growing epidemic of the same chronic diseases that are found in industrialized countries. Moreover, while underfeeding is still an important issue in many of them, emerging economies are also grappling with malnutrition, that has accompanied their nutrition transition and the global food and economic crisis. Nutrigenomics and epigenomics studies tend to demonstrate that early nutrition is not only crucial for children's physical and cognitive development [48-53], but also for their future productivity as adults [92, p. 25; 93]. Such findings demonstrate that the health and economic consequences of underfeeding and malnutrition may be for life and even intergenerational (or transgenerational) [92, p. 22; 93]. Thus, beyond personalized applications aiming to improve individual health or to prevent the onset of chronic 
diseases in individuals, knowledge from nutrigenomics research could be a powerful tool to understand the long-term consequences of underfeeding and malnutrition and could be used to improve prevention and nutrition programs targeting whole populations, including in developing countries. In this respect, nutrigenomics, along with epigenomics, may fall within the global agenda that aims to improve population health, but also food security, availability, stability, and access. Moreover, by targeting diseases that have become a huge burden in both developed and developing nations, nutrigenomics research may also pave the road for a shared agenda in research priorities, decreasing by the same token the aforementioned "10/90 divide".

Yet, much concern has always been expressed around the diversion of scarce resources from other but more evidence-based traditional public health measures and priorities in developing (but also developed) countries. Such an argument is even stronger when it comes to nutrition security and access. However, it is crucial not to overlook the potential utility of nutrigenomics within and for emerging economies. Nutrigenomics will not address the immediate food needs of poor people or entire populations in emerging countries, nor will it put in place high-priority policy measures necessary to improve access to basic nutrition and help populations cope with food prices or the global economic crisis. The recognition of the impact of environmental factors such as socio-economic conditions and disparities on global health, and in particular on the health of populations in these countries remains of the utmost importance. As for any genomics advances, advances in nutrigenomics for global health will have to be assessed with respect to their relative value in the practice and delivery of health care compared with the costs and efficiency of current approaches to public health, disease control, and the provision of basic preventive medicine, medical care and nutrition (Modified from WHO, [86, p. 72]). In any case, food justice and food security must be valued at all levels, in all policies. These are goals in themselves and any tool that could be used to achieve such goals deserves attention [94]. Nutrigenomics could be one of these tools. 
Nutrigenomics raises many hopes and expectations, but it already appears that all potential nutrigenomics applications do not all present the same potential benefits nor represent the same risks in terms of global health, in particular in underserved countries. Given the cultural nature of nutritional habits, the potential variations in genotypes of different ethnic populations, nutrigenomics would not likely serve these countries if their cultural, ethnic or socioeconomic context is not taken into consideration from the design of research protocols to the implementation and evaluation of nutrigenomics applications. Nutrigenomics might hold some of its promises in emerging countries if, and only if, it is tailored to their respective needs, cultures, health systems and priorities. Beyond the costs of such services and social justice issues, one of the major challenges will also be to identify the type of nutrigenetics knowledge and services underserved countries may actually need in terms of efficacy and cost-efficiency. And to achieve such a goal, it is necessary to reflect on how to act wisely considering the many ethical and social-policy implications at stake.

\section{Conclusions and Future Outlook}

The ethical debate surrounding nutrigenomics research, debate framed by values based on research advances and individuals' protection, is increasingly being influenced by the collective values which characterize nutrition science and public health. Although collective values are at the heart of public health activities, the interdisciplinary field of nutrigenomics is raising considerable questions for global health [16, 95]. Solid scientific evidence of nutrigenomics effectiveness and indicators of health determinants for global health need to be evaluated and justified. It has already been argued that a strong medicine and public health partnership in the genomics era is needed for the translation of most scientific discoveries into benefits for population health, including a commitment to evidence-based knowledge integration with several potential genomic applications in practice [95]. These efforts should be complemented with an emphasis on health services research to evaluate outcomes, over both the short and the long term, including attendant costs and benefits in the real world. 
Nutrigenomics may be perceived in two ways: as a market targeting and benefiting welloff individuals and / or as a tool to understand gene-diet interactions that may be used to promote global health and raise awareness that healthy food matters for everyone (everyone who can afford it - many being happy to get any food they can). While certain expectations may be realistic, it is legitimate and necessary to question unreasonable claims and premature translation into commercial applications that may harm the whole field and raise critical ethical issues in terms of global health.

While some of the ethical issues surrounding nutrigenomics are common to any type of genomics research, others are more specific to global health and underserved countries. Many studies in nutrigenomics seem to focus on an individual approach, when personalized nutrition will unlikely solve global health problems and inequalities. In itself, a merely commercial approach, targeting individuals, is far from promoting global health, social justice and equity in access. However, commercial incentives and practices should not be a sufficient reason to claim that nutrigenomics cannot be of benefit for global health, including in developing countries and emerging economies where societies have to cope with the accumulation of serious burdens: underfeeding as well as malnutrition, and an increase of chronic diseases along with a prevalence of infectious diseases that remains extremely high. Nutrigenomics will not and never replace needed and urgent measures aiming to improve global access to basic nutrition. Further, inequities in food access could even be aggravated by potential nutrigenomics applications that would require the ingestion of foods that would not be available in the poorest countries. Yet, despite major ethical and scientific challenges, the potential benefits of nutrigenomics to fight hunger, malnutrition, and chronic diseases must not be overlooked. Certainly, the first tangible benefits resulting from this new field of science for the developing world is a more clear and striking scientific recognition of the devastating effects of underfeeding and malnutrition on genome integrity itself and on the health of whole populations and their descendants. We may hope that as such, nutrigenomics knowledge will give support to a common global health and research agenda that could also benefit the developing world and populations, instead of rich countries and well-off individuals only. 


\section{Acknowledgments}

The authors acknowledge funding support from the Fonds de la recherche en santé du Québec (FRSQ) and the Canadian Institutes of Health Research (CIHR). Thierry Hurlimann would also like to acknowledge the International Institute of Research in Ethics and Biomedicine (IIREB) for its funding support and the opportunity to debate the ethical issues raised by nutrigenomics at the Universidade Federal da Bahia (UFBA), Salvador Da Bahia, Brazil, in November 2008.

\section{Duality/Conflict of Interests}

None declared/applicable.

\section{References}

[1] Ozdemir V, Godard B. Evidenced-based management of nutrigenomics expectations and ELSIs. Pharmacogenomics 2007; 8(8): 1051-62.

[2] Omic-Ethics research group. What is nutrigenomics? http://www.omicsethics.org/research.cfm?rid=1\&omics [Accessed May 20, 2009]. [3] Macfarlane SB, Jacobs M, Kaaya EE. In the name of global health: trends in academic institutions. J Public Health Policy 2008; 29(4): 383-401.

[4] Gostin LO, Taylor AL, Institute for National and Global Health Law at Georgetown University Law Center. Global Health Law: A Definition and Grand Challenges. Public Health Ethics 2008; 1(1): 53-63.

[5] Beaglehole R, Ebrahim S, Reddy S, et al. Prevention of chronic diseases: a call to action. Lancet 2007; 370(9605): 2076-8.

[6] World Health Organization (WHO). Medical genetic services in developing countries. The ethical, legal and social applications of genetic testing and screening (2006). http://www.who.int/entity/genomics/publications/GTS-MedicalGeneticServices-oct06.pdf [Accessed May 20, 2009].

[7] WHO. Action plan for prevention and control of noncommunicable diseases (May 2008). http://www.who.int/mediacentre/events/2008/wha61/issues paper2/en/index.html [Accessed June 17, 2009]. 
[8] WHO. The global burden of diseases: 2004 Update (2008).

http://www.who.int/healthinfo/global burden disease/2004 report update/en/index.html [Accessed June 17, 2009].

[9] Boutayeb A, Boutayeb S. The burden of non communicable diseases in developing countries. Int J Equity Health 2005; 4(1): 2.

[10] Food and Agriculture Organization of the United Nations (FAO). Food prices remain high in developing countries. Newsroom (2009).

http://www.fao.org/news/story/en/item/12660/icode/ [Accessed May 20, 2009].

[11] United Nations World Food Program (WFP). Trends in Staple Food Prices in Selected Vulnerable Countries 2009; 3.

http://documents.wfp.org/stellent/groups/public/documents/ena/wfp199342.pdf

[Accessed June 17, 2009].

[12] World Food Program (WFP). New online price tool shows food still expensive (March 2009). http://www.wfp.org/content/new-online-price-tool-shows-food-stillexpensive [Accessed June 17, 2009].

[13] Brown N, Laffan J, Wight M. High food prices, food security and the international trading system (2008). http://www.dfat.gov.au/trade/focus/081017 food security.html [Accessed June 17, 2009].

[14] FAO. Hunger on the rise: Soaring prices add 75 million people to global hunger rolls. FAO Newsroom (2008). http://www.fao.org/newsroom/en/news/2008/1000923/ [Accessed May 20, 2009].

[15] Brand A. Public health and genetics - a dangerous combination? Eur J Public Health 2005; 15(2): 114-6.

[16] Brand A, Brand $H$, Schulte in den Bäumen T. The impact of genetics and genomics on public health. Eur J Hum Genet 2008; 16(1): 5-13.

[17] Carlson RJ. Preemptive public policy for genomics. J Health Polit Policy Law 2008; 33(1): 39-51.

[18] Holtzman N. What role for public health in genetics and vice versa? Community Genet 2006; 9(1): 8-20.

[19] Bell J. Predicting disease using genomics. Nature 2004; 429(6990): 453-56. 
[20] Evans WE, Relling MV. Moving towards individualized medicine with pharmacogenomics. Nature 2004; 429(6990): 464-8.

[21] Kalow W. Pharmacogenetics and Pharmacogenomics: origin, status, and the hope for personalized medicine. Pharmacogenomics J 2006; 6(3): 162-5.

[22] Kaput J, Rodriguez RL. Nutritional genomics: the next frontier in the postgenomic era. Physiol Genomics 2004; 16(2): 166-77.

[23] Bergmann MM, Görman U, Mathers JC. Bioethical considerations for human nutrigenomics. Annu Rev Nutr 2008; 28: 447-67.

[24] Chavez A, Munoz de Chavez M. Nutrigenomics in public health nutrition: short-term perspectives. Eur J Clin Nutr 2003; 57 (Suppl. 1): S97-100.

[25] Kitajka K, Sinclair AJ, Weisinger RS, et al. Effects of dietary omega-3

polyunsaturated fatty acids on brain gene expression. PNAS 2004; 101(30): 10931-6.

[26] Misiti F, Sampaolese B, Mezzogori D, et al. Protective effect of rhubarb derivatives on amyloid beta (1-42) peptide-induced apoptosis in IMR-32 cells: A case of nutrigenomic. Brain Res Bull 2006; 71(1-3): 29-36.

[27] Guedj F, Sébrié C, Rivals I, et al. Green Tea Polyphenols Rescue of Brain Defects Induced by Overexpression of DYRK1A. PLoS ONE 2009; 4(2): e4606.

[28] Magnus D, Cho MK, Cook-Deegan R. Direct-to-consumer genetic tests: beyond medical regulations? Genome Med 2009; 1(2): 17.

[29] Goddard KA, Robitaille J, Dowling NF, et al. Health-related direct-to-consumer genetic tests: a public health assessment and analysis of practices related to Internetbased tests for risk of thrombosis. Public Health Genomics 2009; 12(2): 92-104. [30] McGuire AL, Burke W. An unwelcome side effect of direct-to-consumer personal genome testing: raiding the medical commons. JAMA 2008; 300(22): 2669-71.

[31] Kuehn BM. Risks and Benefits of Direct-to-Consumer Genetic Testing Remain Unclear. JAMA 2008; 300(13): 1503-5.

[32] Robitaille J. Les services de nutrigénétique offerts sur Internet sont-ils à la hauteur?

L'Observatoire de la génétique 2007; 32. http://www.omicsethics.org/observatoire/cadrages/cadr2007/c no32 07/c no32 07 01.html [Accessed March 15, 2009]. 
[33] Kutz G. Nutrigenetic Testing. Tests Purchased from Four Web Sites Mislead Consumers. Testimony Before the Special Committee on Aging, U.S. Senate. Rep. GAO-06-977T, U.S. Govt. Accountability Off., Washington, DC (2006).

[34] American College of Medical Genetics. ACMG Statement on Direct-To-Consumer Genetic Testing. (April 2008).

http://www.acmg.net/AM/Template.cfm?Section=Policy Statements\&Template=/CM/Co ntentDisplay.cfm\&ContentID=2975 [Accessed May 20, 2009].

[35] Human Genetics Society of Australasia. Issue Paper: Direct to Consumer Genetic Testing. (July 2007).

http://www.hgsa.com.au/images/UserFiles/Attachments/DIRECTTOCONSUMERGENET ICTESTING.pdf [Accessed May 20, 2009].

[36] National Society of Genetic Counselors. Direct to Consumer Genetic Testing. (2007). http://www.nsgc.org/about/position.cfm\#DTC [Accessed May 20, 2009]. [37] Such claims could be found on Sciona Inc. website: http://www.sciona.com/ or http://www.mycellf.com/ [Accessed May, 2009].

[38] See Salugen ${ }^{\mathrm{TM}}$ website: http://www.salugen.com/ [Accessed May 20, 2009]. [39] See AlphaGenics website: http://www.alpha-genics.com/jenejuice.html [Accessed May 20, 2009].

[40] Darnton-Hill I, Margetts B, Deckelbaum R. Public health nutrition and genetics: implications for nutrition policy and promotion. Proc Nutr Soc 2004; 63(1): 173-85. [41] Sutton KH. Considerations for the successful development and launch of personalised nutrigenomic foods. Mutat Res 2007; 622(1-2): 117-21.

[42] Kaput J. Developing the promise of nutrigenomics through complete science and international collaborations. Forum Nutr 2007; 60: 209-23.

[43] Dixon RA, Gang DR, Charlton AJ, et al. Applications of Metabolomics in Agriculture. J Agri Food Chem 2006; 54(24): 8984-94.

[44] Davies KM. Genetic modification of plant metabolism for human health benefits. Mutat Res 2007; 622(1-2): 122-37.

[45] Agriculture and Agri-Food Canada. What are Functional Foods and Nutraceuticals? http://www4.agr.gc.ca/AAFC-AAC/display-afficher.do?id=1171305207040\&lang=eng [Accessed May 20, 2009]. 
[46] See Code Nutrition website: http://www.codenutrition.com/ and Nutrition for your DNA website: http://nutrition4yourdna.com/ [Accessed May 20, 2009]. [47] Harper GS, Lehnert SA, Greenwood PL. Nutrition-Gene Interactions (PostGenomics) in Makkar HPS, Viljoen GJ (Eds.) Applications of Gene-Based Technologies for Improving Animal Production and Health in Developing Countries. pp. 411-28. IAEA, Vienna, Austria: Springer, The Netherlands (2005).

[48] Delage B, Dashwood RH. Dietary manipulation of histone structure and function. Annu Rev Nutr 2008; 28: 347-66.

[49] Aagaard-Tillery KM, Grove K, Bishop J, et al. Developmental origins of disease and determinants of chromatin structure: maternal diet modifies the primate fetal epigenome. J Mol Endocrinol 2008; 41(2): 91-102.

[50] Uauy R, Corvalan C, Dangour AD. Conference on Multidisciplinary approaches to nutritional problems. Rank Prize Lecture. Global nutrition challenges for optimal health and well-being. Proc Nutr Soc 2009; 68(1): 34-42.

[51] Uauy R, Kain J, Mericq V, et al. Nutrition, child growth, and chronic disease prevention. Ann Med 2008; 40(1): 11-20.

[52] Mathers JC. Early nutrition: impact on epigenetics. Forum Nutr 2007; 60: 42-8.

[53] Jirtle RL, Skinner MK. Environmental epigenomics and disease susceptibility. Nat Rev Genet 2007; 8(4): 253-62.

[54] Ozdemir V, Suarez-Kurtz G, Stenne R, et al. Risk Assessment and Communication Tools for Genotype Associations with Multifactorial Phenotypes: The Concept of "Edge Effect" and Cultivating an Ethical Bridge between Omics Innovations and Society. OMICS 2009; 13(1): 43-61.

[55] Wood PA. Potential of nutrigenetics in the treatment of metabolic disorders. Expert Rev Endocrinol Metab 2008; 3(6): 705-713 [56] Subbiah MTR. Understanding the Nutrigenomic Definitions and Concepts at the Food-Genome Junction. OMICS 2008; 12(4): 229-35. [57] Yang QH, Botto LD, Gallagher M, et al. Prevalence and effects of gene-gene and gene-nutrient interactions on serum folate and serum total homocysteine concentrations in the United States: findings from the third National Health and Nutrition Examination Survey DNA Bank. Am J Clin Nutr 2008; 88(1): 232-46. 
[58] Konstantinidou V, Khymenets O, Covas MI, et al. Time Course of Changes in the Expression of Insulin Sensitivity-Related Genes after an Acute Load of Virgin Olive Oil. OMICS. 2009 May 7. [Epub ahead of print].

[59] Janssens AC, van Duijn CM. Genome-based prediction of common diseases: advances and prospects. Hum Mol Genet 2009; 17(R2): R166-73.

[60] Goldstein DB. Common genetic variation and human traits. NEJM 2009; 360(17): 1696-8.

[61] Robitaille J. Nutrigenomics and Personalized Diet: What are the anticipated impacts for research on chronic diseases and public health? Current Pharmacogenomics and Personalized Medicine 2009; 7(2): 106-14.

[62] Wahlqvist ML, Hsu-Hage BHH, Lukito W. Clinical trials in nutrition. Asia Pacific Clin Nutr 1999; 8(3): 231-41.

[63] Afman L, Muller M. Nutrigenomics: from molecular nutrition to prevention of disease. J Am Diet Assoc 2006; 106(4): 569-76.

[64] Farmer Y, Godard B. Public health genomics (PHG). From scientific considerations to ethical integration. Gen Soc and Policy 2007; 3(3): 14-27.

[65] Carlson RJ. The disruptive nature of personalized medicine technologies:

implications for the health care system. Pub Health Genomics 2009; 12(3): 180-4.

[66] Chen S, Kwok OM, Goodson P. US health educators' likelihood of adopting genomic competencies into health promotion._Am J Pub Health 2008; 98(9): 1651-7. [67] Condit CM. How geneticists can help reporters to get their story right. Nature Rev Genet 2007; 8(10): 815-20.

[68] Gwinn M, Khoury MJ. Genomics and Public Health in the United States: Signposts on the Translation Highway. Community Genet 2006; 9(1): 21-6.

[69] Robertson BH, Nicholson JK. New microbiology tools for public health and their implications. Annu Rev Public Health 2005; 26: 281-302.

[70] GRaPH-Int. www.graphint.org [Accessed May 20, 2009].

[71] Barrett DH, Bernier RH, Sowell AL, Centers for Disease Control and Prevention Public Health Ethics Committee Steering Group. Strengthening public health ethics at the centers for disease control and prevention. J Pub Health Manag Practice 2008; 14(4): 348-53. 
[72] Murray TH. Genetic Exceptionalism and "Future Diaries": Is Genetic Information Different from Other Medical Information? In Rothstein MA, ed. Genetic Secrets: Protecting Privacy and Confidentiality in the Genetic Era. New Haven: Yale University Press. (2000).

[73] Hodge JG. Ethical Issues Concerning Testing and Screening in Public Health. Am J Med Genet Part C Semin Med Genet 125C(1): 66-70.

[74] Collins FS, Weiss L, Hudson K. Heredity and Humanity. Have No Fear: Genes Aren't Everything. New Republic online (June 25, 2001).

http://www.arn.org/docs2/news/heredityandhumanity0711.htm [Accessed June 18, 2009].

[75] Brand A, Schroder P, Brand H, et al. Getting ready for the future: integration of genomics into public health research, policy and practice in Europe and globally. Community Genet 2006; 9(1): 67-71.

[76] Callahan D, Jennings B. Ethics and Public Health: Forging a Strong Relationship. Am J Public Health 2002; 92(2): 169-76.

[77] Childress JF, Faden RR, Gaare RD, et al. Public Health Ethics: Mapping The Terrain. J Law Med Ethics 2002; 30(2): 170-8.

[78] CDC, Office of Public Health Genomics. www.cdc.gov/genomics/hugenet/default.htm [Accessed May 20, 2009].

[79] Guttman N, Salmon C. Guilt, fear, stigma and knowledge gaps: ethical issues in public health communication interventions. Bioethics 2004; 18(6): 531-52.

[80] Kaput J. Nutrigenomics research for personalized nutrition and medicine. Curr Opin Biotechnol 2008; 19(2): 110-20.

[81] Pang T, Weatherall D. Genomics and global health. BMJ 2002; 324(7345): 1051-2.

[82] Holm S. Pharmacogenetics, Race and Global Injustice. Developing World Bioethics 2008; 8(2): 82-8.

[83] Kaul I, Grunberg I, Stern MA, eds. Global Public Goods. New York: Oxford University Press. (1999).

[84] Chadwick R. Nutrigenomics, individualism and public health. Proc Nutr Soc 2004; 63(1): 161-6. 
[85] UNESCO The Universal Declaration on the Human Genome and Human Rights. (1997). http://unesdoc.unesco.org/images/0012/001229/122990Eo.pdf [Accessed May 27, 2009].

[86] World Health Organization (WHO). Genomics and the World Health. Report of the Advisory Committee on Health Research. Geneva. (2002).

[87] Selgelid JM. The importance of 'throwing money at' the problem of global health. Indian J Med Ethics 2007; 4(2): 73-5.

[88] Gillies PJ, Krul ES. Using Genetic Variation to Optimize Nutritional Preemption. J Nutr 2007; 137: 270S-274S.

[89] Kaput J, Ordovas JM, Ferguson L, et al. The case for strategic international alliances to harness nutritional genomics for public and personal health. $\mathrm{Br} \mathrm{J}$ Nutr 2005; 94(50): 623-32.

[90] Séguin B, Hardy BJ, Singer PA, et al. Universal health care, genomic medicine and Thailand: investing in today and tomorrow. Nat Rev Genet 2008; 9 (Suppl. 1): S14-9. [91] Alexander D, van Dyck PC. A vision of the future of newborn screening. Pediatrics 2006; 117(5 Pt 2): 350-4.

[92] BMA Board of science. Early life nutrition and lifelong health. British Medical Association. (February 2009).

http://www.bma.org.uk/images/Early\%20life\%20nutrition\%20FINAL tcm41-182859.pdf [Accessed May 27, 2009].

[93] Victora CG, Adair L, Fall C, et al. Maternal and child undernutrition: consequences for adult health and human capital. Lancet 2008; 371(9609): 340-57. [94] Food Ethics Council (FEC). Engineering nutrition: GM crops for global justice? A Food Ethics Council Report, United Kingdom (2003). http://foodethicscouncil.org/files/gmnutrition.pdf [Accessed May 27, 2009]. [95] Khoury MJ, Gwinn M, Burke W, et al. Will genomics widen or help heal the schism between medicine and public health? Am J Pub Health 2007; 33(4): 310-7. 